\section{Compliance of Automated Dispensing Cabinets with Guidelines of the Institute for Safe Medication Practices (US): Comparison between 2010 and 2015}

Most Canadian hospitals use automated dispensing cabinets (ADCs) for some or all aspects of drug dispensing, and ADC use doubled between 2007 and 2014. ${ }^{1,2}$ In 2009, the Centre hospitalier universitaire Sainte-Justine, a 500-bed teaching hospital in Montréal, Quebec, implemented 7 ADCs (Acudose, McKesson Canada, Montréal, Quebec). In the following years, an additional 11 ADCs were implemented.

Compliance scores for the ADCs, in relation to guidelines of the Institute for Safe Medication Practice (ISMP), ${ }^{3}$ were calculated at implementation (i.e., in January and April 2010); these results were published previously in the Canadian Journal of Hospital Pharmacy. ${ }^{4}$ The guidelines specify 12 core processes and 89 individual compliance criteria. ISMP provides a tool for selfassessment of $\mathrm{ADC}$ compliance with the guidelines, with a scoring key for rating each of the 89 criteria from A to E. ${ }^{5}$ We created a point system to allow comparison of results over time: $\mathrm{A}=$ no activity to implement this item ( 1 point), $\mathrm{B}=$ formally discussed but not implemented ( 2 points), $\mathrm{C}=$ partially implemented in some areas (3 points), $\mathrm{D}=$ fully implemented in some areas ( 4 points), and $\mathrm{E}=$ fully implemented throughout the organization ( 5 points). With a multidisciplinary effort to improve the use of ADC technology, the compliance score rose from 67\% (299/445) in January 2010 to $74 \%$ (331/445) in April 2010. Following the April 2010 analysis, we met with both the purchasing group first involved in the tender and the ADC manufacturer, pointing out corrective measures that would, in our opinion, allow the technology to comply with the ISMP guidelines in the future. In 2013, McKesson Canada sold its automation division to Aesynt, a private firm, ${ }^{6}$ and a major software update was provided in 2014.

After the ADCs had been in service for 5 years and following many changes to the software, we repeated the study according to the same methodology used in 2010 (described in detail in the earlier publication ${ }^{4}$ ), to evaluate current compliance of the devices with the ISMP guidelines. These guidelines have not been updated since their original publication in 2008.

In October 2015, 3 pharmacy residents were asked to score the compliance of the current version of the ADCs in relation to the ISMP guidelines. The residents had been previously exposed to the ADCs and trained to use them, so they were able to appreciate and rate compliance with the guidelines. Two senior pharmacists reviewed the suggested scoring. Discrepancies (which occurred for 4 of the criteria) were resolved through consensus.

Table 1 presents the ADC compliance scores recorded in 2010 and 2015. Overall, compliance rose by 19 points, from 331 (74\%) in April 2010 to 350 (79\%) in October 2015 (out of a total of 445 points). Some gains were observed in all but 5 core processes (the exceptions being core processes 2, 3, 6, 9, and 11). Forty-eight of the 95 residual gaps involved core processes 2 , 4, and 7 . Of these, 18 points (19\%) were related to the ADC technology and 77 points (81\%) were related to institutional decisions (or lack thereof). The 2014 software update has reduced some of the residual gaps related to the technology, but display of allergies remains less than optimal, and dosages and administration details for use in the pharmacy profile is still displayed on 2 screens, which could lead a nurse to miss information at the time of administration. Among the residual gaps related to institutional procedures, one example is the local decision to stock multidose bottles of liquid formulations instead of using unit-dose packaging, even though the $\mathrm{ADC}$ is unable to manage multidose bottles precisely. Points were also lost because most of the drugs in the ADC are available at any time through the override function, to limit access delays; in addition, nurses are not required to document the rationale for overrides, as the ISMP guidelines suggest.

Overall, 11 of the 89 criteria had a low compliance score (1 point). For 6 of these, the low score resulted from informed institutional decisions intended to ensure an efficient and safe workflow. Indeed, one of the major obstacles to reaching full compliance is related to institutional practices that differ from the ISMP guidelines. For example, ISMP suggests that users' access should be restricted to their respective clinical areas and that waste should be documented directly on the ADC screen. In the study hospital, access privileges are not granted according to the clinical area because employees move among different sectors of the hospital and because the ADCs in the emergency wards are used as night medication cabinets. In accordance with hospital practices and provincial regulations, waste is still recorded on the medication administration record. If it is accepted that these 6 criteria will never be implemented at the study hospital, compliance reaches $83 \%$ (350/421).

At the study hospital, the total number of reported medication incidents and accidents did not decline between 2010 and 2015, 
Table 1. Compliance Score for Each Core Process in 2010 and 2015 in Relation to Guidelines of the Institute for Safe Medication Practices (ISMP)

Date; \% Score (Raw Score)

\begin{tabular}{|c|c|c|c|c|c|c|}
\hline \multirow[b]{2}{*}{ ISMP Core Process (Max Points) } & & \multirow{2}{*}{ (Points)* } & \multirow{2}{*}{ (Points)t } & \multirow{2}{*}{$\begin{array}{l}\text { Score v. ISMP } \\
\text { Max Score }\end{array}$} \\
\hline & Jan 2010 & Apr 2010 & Aug 2015 & & & \\
\hline $\begin{array}{l}\text { 1. Provide ideal environmental } \\
\text { conditions for use of ADCs (55) }\end{array}$ & $71 \%(39)$ & $73 \%(40)$ & $82 \%(45)$ & 5 & 10 & 55 v. 55 \\
\hline 2. Ensure ADC system security (60) & $60 \%(36)$ & $78 \%(47)$ & $78 \%(47)$ & 0 & 13 & 52 v. 60 \\
\hline 3. Use pharmacy-profiled ADCs (15) & $73 \%(11)$ & $73 \%(11)$ & $67 \%(10)$ & -1 & 5 & 11 v. 15 \\
\hline $\begin{array}{l}\text { 4. Identify information that should } \\
\text { appear on the ADC screen (95) }\end{array}$ & $75 \%(71)$ & $75 \%(71)$ & $81 \%(77)$ & 6 & 18 & 95 v. 95 \\
\hline $\begin{array}{l}\text { 5. Select and maintain proper } \\
\text { ADC inventory (35) }\end{array}$ & $51 \%(18)$ & $66 \%(23)$ & $69 \%(24)$ & 1 & 11 & 31 v. 35 \\
\hline $\begin{array}{l}\text { 6. Select appropriate ADC } \\
\text { configuration (15) }\end{array}$ & $93 \%(14)$ & $93 \%(14)$ & $93 \%(14)$ & 0 & 1 & 15 v. 15 \\
\hline $\begin{array}{l}\text { 7. Define safe ADC restocking } \\
\text { processes (65) }\end{array}$ & $68 \%(44)$ & $71 \%(46)$ & $74 \%(48)$ & 2 & 17 & 65 v. 65 \\
\hline $\begin{array}{l}\text { 8. Develop procedures to ensure } \\
\text { accurate withdrawal of } \\
\text { medications from the ADC (30) }\end{array}$ & $67 \%(20)$ & $70 \%(21)$ & $80 \%(24)$ & 3 & 6 & 26 v. 30 \\
\hline $\begin{array}{l}\text { 9. Establish criteria for ADC } \\
\text { system overrides (30) }\end{array}$ & $63 \%(19)$ & $77 \%(23)$ & $77 \%(23)$ & 0 & 7 & 26 v. 30 \\
\hline $\begin{array}{l}\text { 10. Standardize processes for } \\
\text { transporting medications from } \\
\text { ADC to patient's bedside (20) }\end{array}$ & $80 \%(16)$ & $80 \%(16)$ & $85 \%(17)$ & 1 & 3 & 20 v. 20 \\
\hline $\begin{array}{l}\text { 11. Eliminate process for returning } \\
\text { medications directly to their } \\
\text { original ADC location (5) }\end{array}$ & $80 \%(4)$ & $100 \%(5)$ & $100 \%(5)$ & 0 & 0 & 5 v. 5 \\
\hline $\begin{array}{l}\text { 12. Provide staff education and } \\
\text { competency validation (20) }\end{array}$ & $35 \%(7)$ & $70 \%(14)$ & $80 \%(16)$ & 2 & 4 & 20 v. 20 \\
\hline Total (445) & $67 \%(299)$ & 74\% (331) & $79 \%(350)$ & 19 & 95 & $421 \neq$ v. 445 \\
\hline $\begin{array}{l}\text { No. of reported medication } \\
\text { incidents, accidents, or events }\end{array}$ & $\begin{array}{c}1865 \\
(2009 / 2010) \\
\end{array}$ & $\begin{array}{c}2150 \\
(2010 / 2011) \\
\end{array}$ & $\begin{array}{c}2179 \\
(2014 / 2015) \\
\end{array}$ & NA & NA & \\
\hline
\end{tabular}

$\overline{\mathrm{ADC}}=$ automated dispensing cabinet, $\mathrm{max}=$ maximum, $\mathrm{NA}=$ not applicable.

*Calculated as score in August 2015 minus score in April 2010.

+Calculated as ideal score minus score in August 2015.

fTotal score achieved in August 2015 as a proportion of the realistic maximum score for the institution: $350 / 421$ (83\%).

despite the introduction of ADCs. Although monitoring of the overall number of incidents did not indicate any risk reduction associated with the implementation of ADCs, we believe that any compliance audit of the use of technology should include a formal evaluation of risk reduction. In Quebec, the system for reporting and monitoring incidents and accidents does not currently include specific terms to identify events associated with ADCs. The ISMP published comparative data collected from health care centres that submitted their self-assessment results between June 2009 and February 2010.7 The mean score for 300- to 499-bed hospitals (comparable in size to ours) was 350 points, which confirms that our use of and procedures for ADCs reflect what is done elsewhere.

In the coming year, further local efforts will be dedicated to improving the compliance score. The primary action will consist of improving the safety of the medication-use process related to controlled drug dispensing. Additional audits will be conducted to monitor transactions recorded in the ADCs. Systematic use of bar codes when filling ADCs will also be implemented. The use of bar codes could decrease potential dispensing errors resulting from selection of an incorrect medication or dosage. Increased surveil- lance will be used to monitor transactions involving the override function and to identify situations where overrides could be avoided. Reinforcement will be applied to sensitize ADC users to the risks of this practice and to empower them to avoid unnecessary overrides. Users will also be reminded to complete an incident report when a problematic situation is observed with the ADCs. It is anticipated that audits of these reports will help to identify potentially higher-risk areas and will prompt implementation of measures to make these processes safer.

This practice review has illustrated the challenge of fully complying with the ISMP guidelines. Hospitals should be encouraged to perform such compliance audits not only during the implementation phase, but also periodically once the technology is in place. Although the ADC technology may appear easy to implement, it requires sustained efforts and repeated audits to optimize its use and to achieve the promised gains.

\section{References}

1. Bonnici A, Bornstein C, Bussières JF, Doucette D, Hall K, Jones R, et al., editors. Hospital pharmacy in Canada 2013/2014 report. Eli Lilly; 2014 [cited 2015 Oct 29]. Available from: www.lillyhospitalsurvey.ca/hpc2/content/ 2015_report/FULL-2015.pdf 
2. Automated dispensing cabinets in the Canadian environment. ISMP Can Saf Bull. 2007 [cited 2007 Jun 29];7(3):1-3. Available from: www.ismp-canada. org/download/safetyBulletins/ISMPCSB2007-03ADCs.pdf

3. Institute for Safe Medication Practice (ISMP) guidance on the interdisciplinary safe use of automated dispensing cabinets. Horsham (PA): Institute for Safe Medication Practice; 2008 [cited 2015 Oct 29]. Available from: https:// www.ismp.org/Tools/guidelines/ADC/default.asp;

4. Brisseau L, Bussières JF, Lebel D, Atkinson S, Robinette L, Fortin S, et al. Utilisation de lignes directrices dans le cadre de l'implantation de cabinets automatisés décentralisés en établissement de santé. Can J Hosp Pharm. 2011; 64(2):104-15.

5. ISMP medication safety self assessment for automated dispensing cabinets; an invitation to participate. Horsham (PA): Institute for Safe Medication Practice; 2009 [cited 2015 Oct 29]. Available from: https://www.ismp.org/ selfassessments/ADC/Survey.pdf

6. McKesson Canada has signed an exclusive distribution agreement with Aesynt [news release]. Montréal (QC): McKesson Canada; 2013 Nov 12 [cited 2015 Nov 16]. Available from: https://www.mckesson.ca/-/mckesson-canadahas-signed-an-exclusive-distribution-agreement-with-aesynt

7. 2009 ISMP medication safety self assessment for automated dispensing cabinets; results workbook. Horsham (PA): Institute for Safe Medication Practice; 2009 [cited 2015 Oct 29]. Available from: https://www.ismp.org/ selfassessments/ADC/ISMP_ADC_Workbook_posted.pdf

\section{Emmy Bernier, PharmD}

Pharmacy Resident

Lavina Yu, PharmD

Pharmacy Resident

Julie Rivard, PharmD

Pharmacy Resident

Suzanne Atkinson, BPharm, MSC

Assistant Director - Pharmaceutical Services

Jean-François Bussières, BPharm, MSC, MBA, FCSHP

Director

Pharmacy Practice Research Unit and Pharmacy Department

Centre hospitalier universitaire Sainte-Justine

Montréal, Quebec

Emmy Bernier, Lavina Yu, and Julie Rivard are also MSc candidates and Jean-François Bussières is also a Clinical Professor with the Faculty of Pharmacy, Université de Montréal, Montréal, Quebec.

Competing interests: None declared.

\section{BEST..is better}

\section{One resource for all types of compounding by pharmacies}

\section{WHAT'S INSIDE?}

- Information for pharmacists, pharmacy technicians, planners, architects, engineers - and others who are involved in decisions or activities that affect compounding

- Guidelines for aseptic compounding, non-aseptic compounding, and compounding which involves hazardous drugs-including radiopharmaceuticals

- Best and leading guidelines on topics such as training. planning and designing the physical environment, developing an air quality strategy, cleaning and decontaminating areas, monitoring the environment, garbing and hand hygiene, developing compounding procedures, documenting, and much more-all in only 230 pages

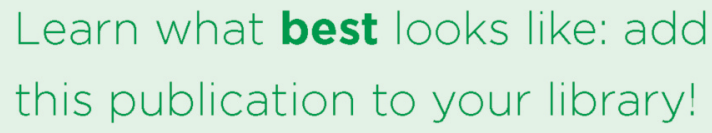

2014

HAVE A SNEAK PEEK OR ORDER AT: www.cshp.ca/compounding CSHP MEMBERS PAY A DISCOUNTED PRICE

Canadian Society of Hospital Pharmacists Société canadienne des pharmaciens d'hôpitaux 